\title{
Fuzzy Environmental Model for Evaluating Water Quality of Sangam Zone during Maha Kumbh 2013
}

\author{
Pankaj Srivastava, ${ }^{1}$ Anjali Burande, ${ }^{2}$ and Neeraja Sharma ${ }^{1}$ \\ ${ }^{1}$ Department of Mathematics, Motilal Nehru National Institute of Technology, Allahabad, Uttar Pradesh 211004, India \\ ${ }^{2}$ Department of Mathematics, Dayanand College of Commerce, Latur, Maharashtra 413512, India \\ Correspondence should be addressed to Neeraja Sharma; 06.neeraja@gmail.com
}

Received 25 May 2013; Accepted 8 July 2013

Academic Editor: Baoding Liu

Copyright (c) 2013 Pankaj Srivastava et al. This is an open access article distributed under the Creative Commons Attribution License, which permits unrestricted use, distribution, and reproduction in any medium, provided the original work is properly cited.

It is a well-known fact that water is the basic need of human beings. The industrial wastes nearby rivers and several anthropogenic activities are responsible for deteriorating water quality of rivers in India. The present research paper deals with the design and development of soft computing system to assess the water quality of rivers Ganga and Yamuna during the Maha Kumbh 2013 in and around Sangam Zone, Allahabad, by making use of physicochemical parameters relationship.

\section{Introduction}

The role of water in human life is important as it plays a vital role in the mechanics of human body. Human body is a water machine designed to run primarily on water and minerals. The movement of water within our cellular system also transports vital blood plasma, $92 \%$ of which is made up of water. It confirms the quality of water we consume will have severe impact on our overall state of health. Our brain contains over $80 \%$ water and controls each and every process that happens inside our body. Considering the vital role that water plays in our brain and nervous system is key to longevity. The purity of water we drink causes impact on our strength and energy level.

Hindus believe that river Ganga is physically and spiritually pure and it removes all sins committed by human being during life time, normally by taking a dip in it. The mythological belief of Hindus regarding Ganga is on its threshold due to dangerous chemical contaminants related to industries and sewage system of towns close to it as well as human and animal wastes, and water quality deteriorates rapidly downstream. Nonetheless, $80 \%$ of the health problems in contemporary India come from waterborne diseases.

In order to improve water quality of rivers a systematic scientific approach has been made by Meyer [1], Harmancioglu et al. [2], Rosemary et al. [3], and many other scientists in terms of their chemical, biological, and nutrient constituents. However, discrepancies appeared due to the uncertainty in the quality criteria employed and the imprecision, vagueness, or fuzziness in the decision-making output values.

It is a well-known fact that decision-making processes in real life problems are too complex, and to handle such issue Zadeh introduced the concept of fuzzy [4] and consequently he published a series of papers that show how his idea can be used in real applications. The decision-making process in the presence of fuzzy variables was introduced by Jain [5] and later on Bellman and Zadeh [6] proposed application of fuzzy tools in the fuzzy environment. During the last phase of the twentieth century Cho et al. [7] designed an algorithm which described the computation of the degree of match (DM) between the antecedent part of a fuzzy classification rule and an assertion given by a user when imprecise and precise propositions are mixed freely in a fuzzy expert classification system. Kumar [8] has used the concept of degree of match in fuzzy environment to study the water pollution of Sangam Zone, Allahabad, in 2004, and assessment of quality of water rivers Ganga and Yamuna during Ardh Kumbh 2007 was studied by Yadav [9] under the supervision of Pankaj Srivastava.

Medical science due to its uncertain features and imprecise information has been center of attraction for soft computing experts. In order to study cardiac analysis phenomena 
Pandey et al. [10] gave a fuzzy analysis of ECG diagnosis using the principles of fuzzy logic for cardiac analysis with the knowledge of medical experts. Recently P. Srivastava and A. Srivastava $[11,12]$ designed a fuzzy expert system to determine coronary heart disease (CHD) risk factor and effective diagnosis system for risk assessment of hypertension, respectively. Srivastava and Sharma introduced a soft computing decisionmaking model for medical diagnosis [13]. Srivastava et al. [14] proposed a soft computing classification criterion to design and develop user friendly diagnostic system for Hepatitis B. Srivastava et al. [15] proposed soft computing diagnostic system for diabetes that sharpens the diagnostic process and guides patients to evolve strategies to control their sugar level.

Fuzzy relational equations were introduced in 1976 by Sanchez [16] who discussed application of fuzzy relational equation in medical issues. Rotshtein et al. [17] proposed fuzzy models of diagnosis on the basis of fuzzy relational equations. In the present paper, an attempt is made to develop a user friendly Fuzzy Environmental Model for the evaluation of the water quality of Sangam Zone during Maha Kumbh 2013 using pairwise comparison matrices for making decision on the basis of Zadeh's compositional rule of inference process for fuzzy relational equation $Y=X \circ R$ [18]. The development of fuzzy information system incorporates fuzzification process which is an essential feature of model building, and this fuzzification with the help of Saaty's point scale [19] is done on the basis of expert information about cause-paired comparisons in this paper.

\section{Materials and Method}

Water quality is determined by its physical, chemical, and bacteriological characteristics and in order to assess quality of water, data of three major ghats, where majority of people take dip in rivers Ganga and Yamuna, have been taken during Maha Kumbh 2013. In practicular, Ram Ghat, Sangam Nose, and Saraswati Ghat's water was taken and an attempt was made to assess physiochemical behaviour and suitability for bathing and swimming on the basis of fuzzy modeling. The parameters considered for analysis are turbidity $(\mathrm{T})$, dissolved oxygen (DO), biochemical oxygen demand (BOC), $\mathrm{pH}$ value (pH), and Fecal Coliform (FC) Figures 1, 2, 3, 4, 5, and 6.

In order to design a user friendly environment model for evaluating water quality of rivers Ganga and Yamuna during Maha Kumbh 2013, we propose the following fuzzy algorithm.

Step 1 (initial phase).

[1.1] Selection of imprecise and vague features: set $X=$ $\left\{X_{i}, i=\overline{1, n}\right\}$ for proposed system and categorize them in fuzzy linguistic terms.

[1.2] Develop membership function $M\left(X_{i}\right), i=\overline{1, n}$, for each fuzzy linguistic term.

[1.3] We use fuzzy relational equation $Y=X \circ R$, where $R=\left[r_{i j}\right]$, where $r_{i j} \in[0,1], i=\overline{1, n}$ and $j=\overline{1, m}$, 。 is

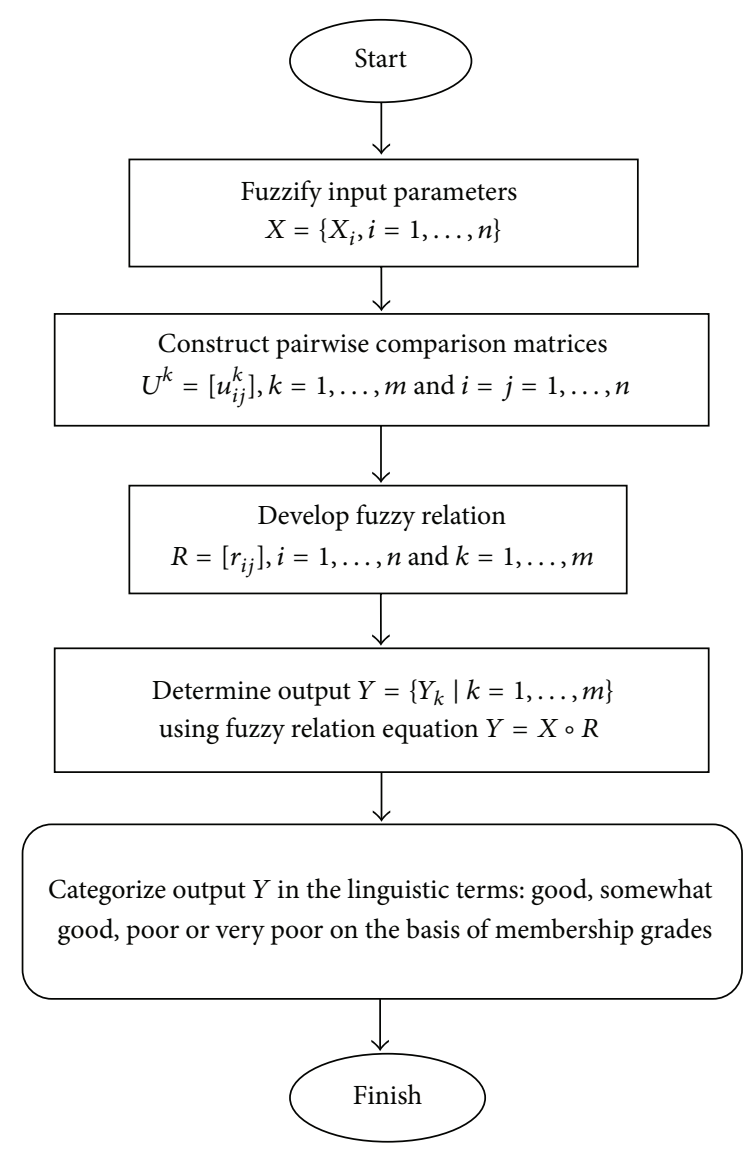

FIgURE 1: Flow chart.

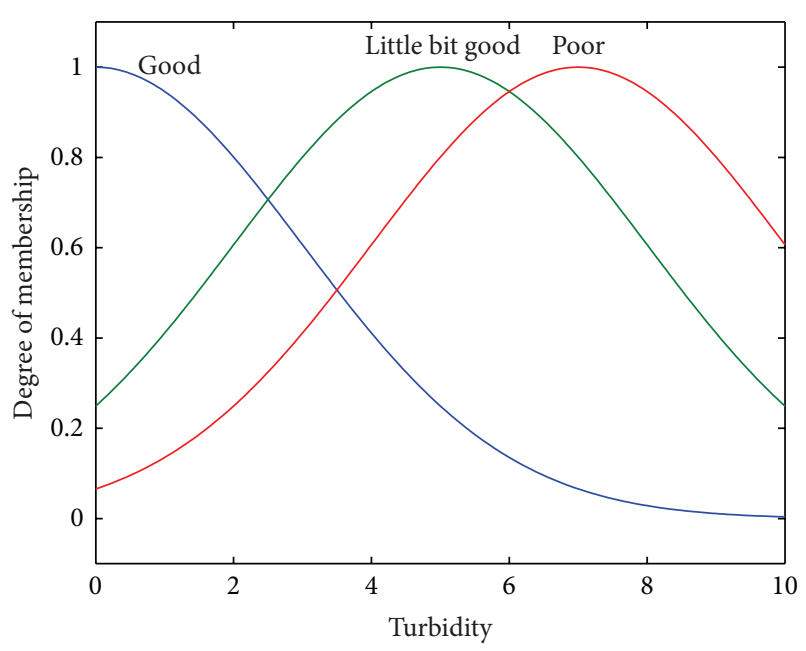

FIGURE 2: Turbidity.

the max-product composition, which gives fuzzy sets for different category of output $Y=\left\{Y_{j}, j=\overline{1, m}\right\}$.

Step 2 (construction of fuzzy relation $R$ ).

[2.1] Develop pairwise comparison matrices $U^{j}=\left[u_{i k}^{j}\right]$, where $u_{i k}^{j} \in[0,1], i=k=\overline{1, n}$ and $j=\overline{1, m}$, among 


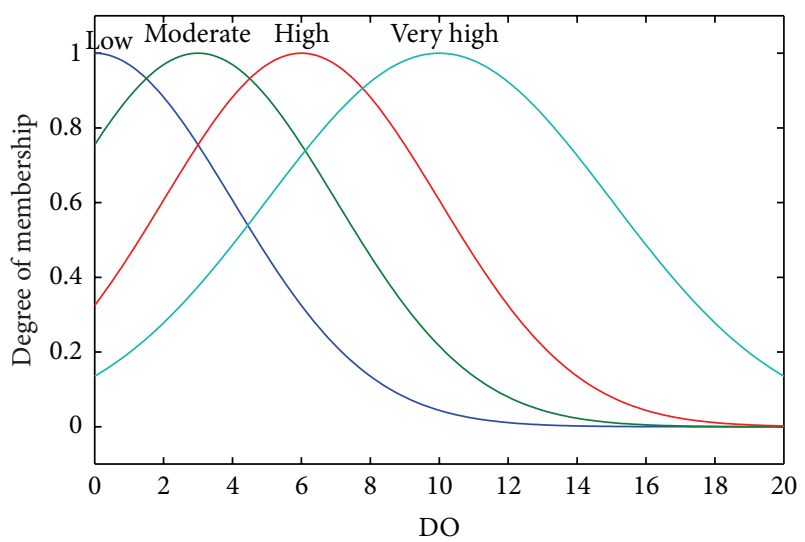

FIGURE 3: Dissolved oxygen.

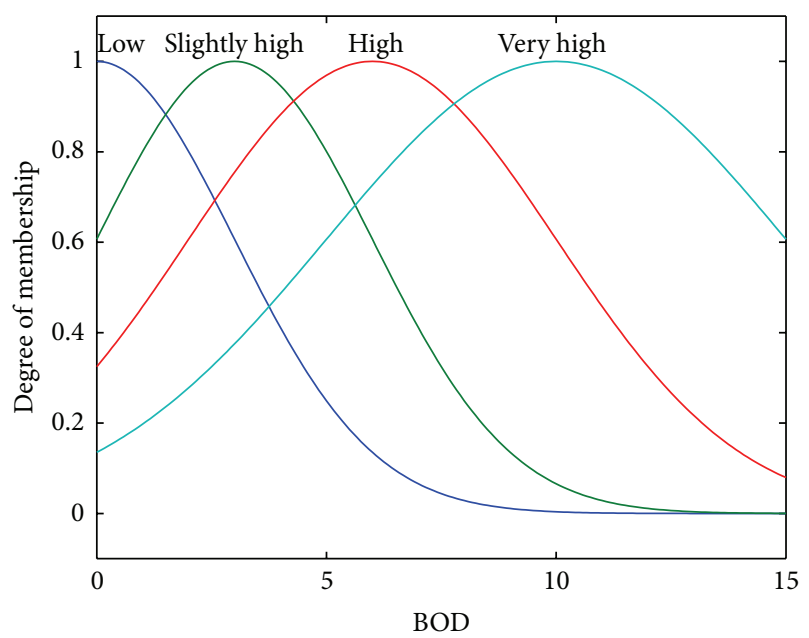

Figure 4: Biochemical oxygen dissolved.

vague parameters $X=\left\{X_{i}, i=\overline{1, n}\right\}$ using Saaty's pairwise comparisons [2].

[2.2] Develop $R=\left[r_{i j}\right]$, such that $r_{i j}=1 /\left(u_{i 1}^{j}+u_{i 2}^{j}+\cdots+u_{i n}^{j}\right)$.

[2.3] Normalize the membership grade of $r_{i j} \in[0,1]$.

Step 3 (evaluation of output).

[3.1] Evaluate $Y$ using max-product composition for different values of vague parameters $X$ in fuzzy relation equation $Y=X \circ R$.

Figure 1 represents the algorithm.

\subsection{Input Parameters}

2.1.1. Turbidity (T). Turbidity is categorized into three fuzzy sets with membership functions as follows:

(1) Good (G): 0-3 NTU,

(2) Little bit good (LG): 3-7 NTU,

(3) Poor (P): 7-10 NTU.

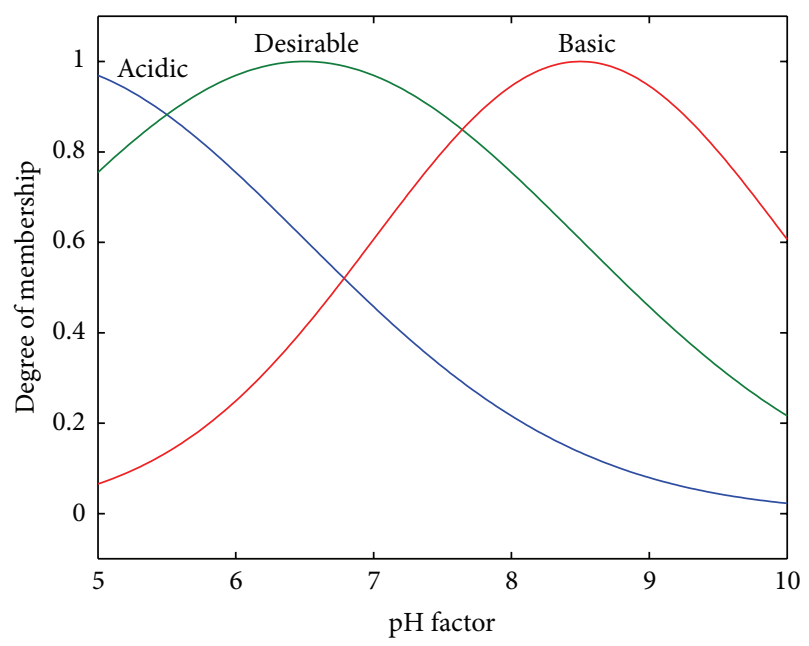

FIGURE 5: pH factor.

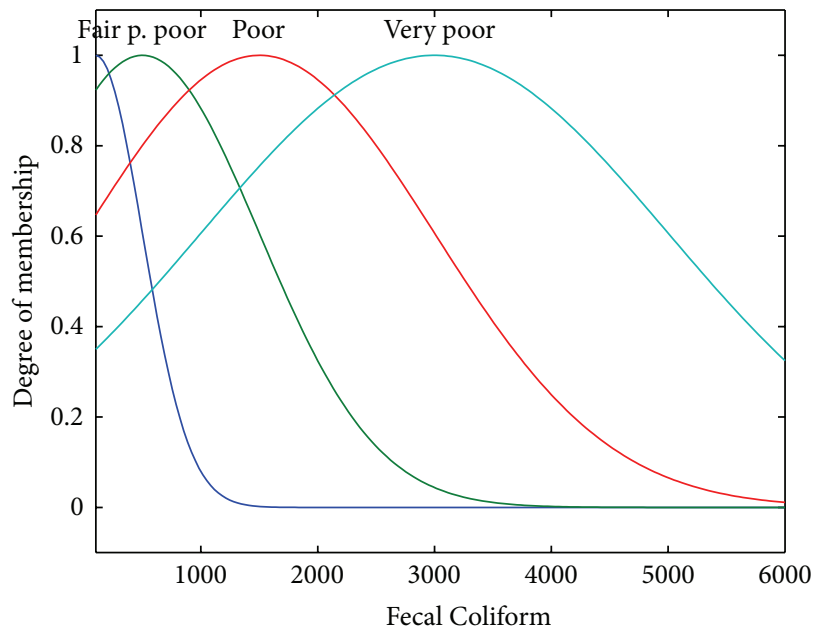

FIgURE 6: Fecal Coliform.

(i) $\mu_{\text {Good }}(x)=\exp ^{-(x-0)^{2} / 18}$,

(ii) $\mu_{\text {LittleBitGood }}(x)=\exp ^{-(x-3)^{2} / 32}$,

(iii) $\mu_{\text {Poor }}(x)=\exp ^{-(x-7)^{2} / 18}$.

2.1.2. Dissolved Oxygen (DO). DO is categorized into four fuzzy sets and their membership functions are given below:

(1) Low (L): 0-3 mg/L,

(2) Moderate $(\mathrm{M}): 3-5 \mathrm{mg} / \mathrm{L}$,

(3) High $(\mathrm{H}): 6-8 \mathrm{mg} / \mathrm{L}$,

(4) Very high (VH): 8-11 mg/L.

(i) $\mu_{\text {Low }}(x)=\exp ^{-(x-0)^{2} / 18}$,

(ii) $\mu_{\text {Moderate }}(x)=\exp ^{-(x-3)^{2} / 8}$,

(iii) $\mu_{\text {High }}(x)=\exp ^{-(x-6)^{2} / 8}$,

(iv) $\mu_{\text {VeryHigh }}(x)=\exp ^{-(x-8)^{2} / 18}$. 
2.1.3. Biochemical Oxygen Dissolved (BOD). BOD is categorized into four fuzzy sets and their membership functions are given below:

(1) Low (L): 0-3 mg/L,

(2) Slightly high $(\mathrm{SH}): 3-6 \mathrm{mg} / \mathrm{L}$,

(3) High (H): 6-10 mg/L,

(4) Very high (VH): $10-15 \mathrm{mg} / \mathrm{L}$.

(i) $\mu_{\text {Low }}(x)=\exp ^{-(x-0)^{2} / 18}$,

(ii) $\mu_{\text {SlightlyHigh }}(x)=\exp ^{-(x-3)^{2} / 18}$,

(iii) $\mu_{\text {High }}(x)=\exp ^{-(x-6)^{2} / 32}$,

(iv) $\mu_{\text {VeryHigh }}(x)=\exp ^{-(x-10)^{2} / 50}$.

2.1.4. $p H$ Factor $(p H)$. The $\mathrm{pH}$ factor is categorized into three fuzzy sets and their membership functions are given below:

(1) Acidic (A): <6.5,

(2) Desirable (D): 6.5-8.5,

(3) Basic (B): 8.5.

(i) $\mu_{\text {Acidic }}(x)=\exp ^{-(x-4.5)^{2} / 8}$,

(ii) $\mu_{\text {Desirable }}(x)=\exp ^{-(x-6.5)^{2} / 8}$,

(iii) $\mu_{\text {Basic }}(x)=\exp ^{-(x-8.5)^{2} / 4.5}$.

2.1.5. Fecal Coliform (FC). FC is categorized into four fuzzy sets and their membership functions are given below:

(1) Fair (F): <500,

(2) Partly poor (PP): 500-1500,

(3) Poor (P): 1500-3000,

(4) Very poor (VP): $>3000$.

(i) $\mu_{\text {Fair }}(x)=\exp ^{-(x-100)^{2} / 2 x 400^{2}}$,

(ii) $\mu_{\text {PartlyPoor }}(x)=\exp ^{-(x-500)^{2} / 2 \times 1000^{2}}$,

(iii) $\mu_{\text {Poor }}(x)=\exp ^{-(x-1500)^{2} / 2 \times 1500^{2}}$,

(iv) $\mu_{\text {VeryPoor }}(x)=\exp ^{-(x-3000)^{2} / 2 \times 2000^{2}}$.

2.2. Evaluation of Water Quality. Estimation of water quality of rivers, namely, Ganga and Yamuna, during Maha Kumbh 2013 is carried out using compositional Zadeh's rule of inference [14] represented by fuzzy relational equation:

$$
Y=X \circ R
$$

where $X=\left\{\right.$ turbidity $=x_{1}, \mathrm{DO}=x_{2}, \mathrm{BOD}=x_{3}, \mathrm{pH}=$ $\left.x_{4}, \mathrm{FC}=x_{5}\right\}$ is fuzzy causes vector for estimation of water quality; $Y=\left\{\operatorname{good}=y_{1}\right.$, somewhat $\operatorname{good}=y_{2}$, poor $=$ $y_{3}$, very poor $\left.=y_{4}\right\}$ is fuzzy vector for the water quality as the output is categorized into four fuzzy sets: $\operatorname{good}(G)$, somewhat good (SG), poor (P), and very poor (VP); and $R$ is the fuzzy
TABLE 1

\begin{tabular}{ccccccc}
\hline & $x_{1}$ & $x_{2}$ & $x_{3}$ & $x_{4}$ & $x_{5}$ & $x_{6}$ \\
\hline$x_{1}$ & 1 & 4 & 3 & 3 & 5 & 9 \\
$U_{2}=$ & $1 / 4$ & 1 & $3 / 4$ & $3 / 4$ & $2 / 4$ & $9 / 4$ \\
$x_{3}$ & $1 / 3$ & $4 / 3$ & 1 & 1 & $2 / 3$ & $9 / 3$ \\
$x_{4}$ & $1 / 3$ & $4 / 3$ & 1 & 1 & $2 / 3$ & $9 / 3$ \\
$x_{5}$ & $1 / 5$ & $4 / 5$ & $3 / 5$ & $3 / 5$ & 1 & $9 / 5$ \\
$x_{6}$ & $1 / 9$ & $4 / 9$ & $3 / 9$ & $3 / 9$ & $2 / 9$ & 1 \\
\hline
\end{tabular}

TABLE 2

\begin{tabular}{|c|c|c|c|c|c|c|c|}
\hline & & $x_{1}$ & $x_{2}$ & $x_{3}$ & $x_{4}$ & $x_{5}$ & $x_{6}$ \\
\hline \multirow{6}{*}{$U^{2}=$} & $x_{1}$ & 1 & 5 & 4 & 5 & 6 & 9 \\
\hline & $x_{2}$ & $1 / 5$ & 1 & $4 / 5$ & 1 & $6 / 5$ & $9 / 5$ \\
\hline & $x_{3}$ & $1 / 4$ & $5 / 4$ & 1 & $5 / 4$ & $6 / 4$ & $9 / 4$ \\
\hline & $x_{4}$ & $1 / 5$ & 1 & $4 / 5$ & 1 & $6 / 5$ & $9 / 5$ \\
\hline & $x_{5}$ & $1 / 6$ & $5 / 6$ & $4 / 6$ & $5 / 6$ & 1 & $9 / 6$ \\
\hline & $x_{6}$ & $1 / 9$ & $5 / 9$ & $4 / 9$ & $5 / 9$ & $6 / 9$ & 1 \\
\hline
\end{tabular}

TABLE 3

\begin{tabular}{ccccccc}
\hline & $x_{1}$ & $x_{2}$ & $x_{3}$ & $x_{4}$ & $x_{5}$ & $x_{6}$ \\
\hline$x_{1}$ & 1 & 4 & 6 & 6 & 7 & 9 \\
$x_{2}$ & $1 / 4$ & 1 & $6 / 4$ & $6 / 4$ & $7 / 4$ & $9 / 4$ \\
$x_{3}$ & $1 / 6$ & $4 / 6$ & 1 & 1 & $7 / 6$ & $9 / 6$ \\
$x_{4}$ & $1 / 6$ & $4 / 6$ & 1 & 1 & $7 / 6$ & $9 / 6$ \\
$x_{5}$ & $1 / 7$ & $4 / 7$ & $6 / 7$ & $6 / 7$ & 1 & $9 / 7$ \\
$x_{6}$ & $1 / 9$ & $4 / 9$ & $6 / 9$ & $6 / 9$ & $7 / 9$ & 1 \\
\hline
\end{tabular}

TABLE 4

\begin{tabular}{ccccccc}
\hline & $x_{1}$ & $x_{2}$ & $x_{3}$ & $x_{4}$ & $x_{5}$ & $x_{6}$ \\
\hline$U^{4}=$ & 1 & 3 & 7 & 6 & 8 & 9 \\
$x_{1}$ & $1 / 3$ & 1 & $7 / 3$ & $6 / 3$ & $8 / 3$ & $9 / 3$ \\
$x_{2}$ & $1 / 7$ & $3 / 7$ & 1 & $6 / 7$ & $8 / 7$ & $9 / 7$ \\
$x_{3}$ & $1 / 6$ & $3 / 6$ & $7 / 6$ & 1 & $8 / 6$ & $9 / 6$ \\
$x_{4}$ & $1 / 8$ & $3 / 8$ & $7 / 8$ & $6 / 8$ & 1 & $9 / 8$ \\
$x_{5}$ & $1 / 9$ & $3 / 9$ & $7 / 9$ & $6 / 9$ & $8 / 9$ & 1 \\
$x_{6}$ & & & & & & \\
\hline
\end{tabular}

relational matrix such that $R=\left[r_{i j}\right]$, where $r_{i j} \in[0,1], i=\overline{1,5}$ and $j=\overline{1,4}$, o is the max-product composition.

The four pairwise comparison matrices among parameters for each linguistic term of water quality are given in Tables 1, 2, 3, and 4 .

The following fuzzy relation $R$ is evaluated from the above-mentioned four pairwise comparison matrices as given in the algorithm:

$$
R=\left(\begin{array}{llll}
0.13 & 0.08 & 0.08 & 0.07 \\
0.45 & 0.42 & 0.30 & 0.22 \\
0.35 & 0.33 & 0.45 & 0.52 \\
0.35 & 0.42 & 0.45 & 0.44 \\
0.23 & 0.50 & 0.53 & 0.59
\end{array}\right)
$$

Three important places, Ram Ghat, Sangam Nose, and Saraswati Ghat, were selected for the assessment of water quality of rivers Ganga and Yamuna during Maha Kumbh 
2013 on important occasions, that is, Mauni Amavasya (Feb. 10, 2013), Basant Panchami (Feb. 15, 2013), and Maghi Purnima (Feb. 25, 2013) for bathing due to religious beliefs.

2.2.1. On February 10, 2013. (I) At Ram Ghat. Water has the following values for input parameters and their membership grades:

$$
\begin{gathered}
X=\left\{\left(x_{1}=5.6,0.809\right),\left(x_{2}=10.6,0.965\right),\left(x_{3}=5.6,0.687\right),\right. \\
\left.\left(x_{4}=8.5,0.606\right),\left(x_{5}=4000,0.883\right)\right\} .
\end{gathered}
$$

The quality of water at Ram Ghat on Mauni Amavasya is evaluated as below using fuzzy relational equation:

$$
\begin{gathered}
Y=\left(\begin{array}{llll}
y_{1} & y_{2} & y_{3} & y_{4}
\end{array}\right), \\
Y=X \circ R \\
=\left(\begin{array}{llll}
0.44 & 0.46 & 0.47 & 0.52
\end{array}\right),
\end{gathered}
$$

which states that water quality is very poor for bathing at Ram Ghat.

(II) At Sangam. Water has the following values for input parameters and their membership grades:

$$
\begin{gathered}
X=\left\{\left(x_{1}=5.3,0.85\right),\left(x_{2}=9.7,0.85\right),\left(x_{3}=5.0,0.80\right),\right. \\
\left.\left(x_{4}=8.56,0.59\right),\left(x_{5}=5500,0.46\right)\right\} .
\end{gathered}
$$

The quality of water at Sangam on Mauni Amavasya is evaluated as below:

$$
\begin{aligned}
Y & =X \circ R \\
& =\left(\begin{array}{llll}
0.38 & 0.32 & 0.54 & 0.42
\end{array}\right),
\end{aligned}
$$

which states that water quality is poor for bathing at Sangam.

(III) At Saraswati Ghat. Water has the following values for input parameters and their membership grades:

$$
\begin{gathered}
X=\left\{\left(x_{1}=5.0,0.88\right),\left(x_{2}=8.9,0.96\right),\left(x_{3}=1.8,0.84\right),\right. \\
\left.\left(x_{4}=8.35,0.65\right),\left(x_{5}=2500,0.61\right)\right\} .
\end{gathered}
$$

The quality of water at Saraswati Ghat on Mauni Amavasya is evaluated as below:

$$
\begin{aligned}
Y & =X \circ R \\
& =\left(\begin{array}{llll}
0.43 & 0.40 & 0.39 & 0.24
\end{array}\right) .
\end{aligned}
$$

which states that water quality is good for bathing at Saraswati Ghat.
2.2.2. On February 15, 2013. (I) At Ram Ghat. Water has the following values for input parameters and their membership grades:

$$
\begin{gathered}
X=\left\{\left(x_{1}=4.6,0.92\right),\left(x_{2}=10.7,0.67\right),\left(x_{3}=5.4,0.73\right),\right. \\
\left.\left(x_{4}=8.4,0.634\right),\left(x_{5}=4950,0.622\right)\right\} .
\end{gathered}
$$

The quality of water at Ram Ghat on Basant Panchami is evaluated as below using fuzzy relational equation:

$$
\begin{gathered}
Y=\left(\begin{array}{llll}
y_{1} & y_{2} & y_{3} & y_{4}
\end{array}\right), \\
Y=X \circ R \\
=\left(\begin{array}{llll}
0.30 & 0.33 & 0.33 & 0.38
\end{array}\right),
\end{gathered}
$$

which states that water quality is very poor for bathing at Ram Ghat.

(II) At Sangam. Water has the following values for input parameters and their membership grades:

$$
\begin{gathered}
X=\left\{\left(x_{1}=4.3,0.95\right),\left(x_{2}=9.8,0.835\right),\left(x_{3}=5.0,0.80\right),\right. \\
\left.\left(x_{4}=8.43,0.63\right),\left(x_{5}=6300,0.256\right)\right\} .
\end{gathered}
$$

The quality of water at Sangam on Basant Panchmi is evaluated as below:

$$
\begin{aligned}
Y & =X \circ R \\
& =\left(\begin{array}{llll}
0.38 & 0.35 & 0.36 & 0.42
\end{array}\right),
\end{aligned}
$$

which states that water quality is very poor for bathing at Sangam.

(III) At Saraswati Ghat. Water has the following values for input parameters and their membership grades:

$$
\begin{gathered}
X=\left\{\left(x_{1}=4.1,0.96\right),\left(x_{2}=8.9,0.96\right),\left(x_{3}=1.8,0.84\right),\right. \\
\left.\left(x_{4}=8.32,0.66\right),\left(x_{5}=1900,0.41\right)\right\} .
\end{gathered}
$$

The quality of water at Saraswati Ghat on Basant Panchmi is evaluated as below:

$$
\begin{aligned}
Y & =X \circ R \\
& =\left(\begin{array}{llll}
0.43 & 0.40 & 0.38 & 0.37
\end{array}\right),
\end{aligned}
$$

which indicates the water quality is good for bathing at Saraswati Ghat.

2.2.3. On February 25, 2013. (I) At Ram Ghat. Water has the following values for input parameters and their membership grades:

$$
\begin{gathered}
X=\left\{\left(x_{1}=4.8,0.90\right),\left(x_{2}=9.4,0.90\right),\left(x_{3}=4.8,0.84\right),\right. \\
\left.\left(x_{4}=8.33,0.66\right),\left(x_{5}=4500,0.76\right)\right\} .
\end{gathered}
$$


TABLE 5

\begin{tabular}{lccc}
\hline & February 10 & February 15 & February 25 \\
\hline Ram Ghat & Very poor & Very poor & Very poor \\
Sangam Nose & Poor & Very poor & Very poor \\
Saraswati Ghat & Good & Good & Very poor \\
\hline
\end{tabular}

The quality of water at Ram Ghat on Maghi Purnima is evaluated as below using fuzzy relational equation:

$$
\begin{aligned}
Y=\left(\begin{array}{llll}
y_{1} & y_{2} & y_{3} & y_{4}
\end{array}\right), \\
Y=X \circ R \\
=\left(\begin{array}{llll}
0.41 & 0.38 & 0.39 & 0.44
\end{array}\right),
\end{aligned}
$$

which states that water quality is very poor for bathing at Ram Ghat.

(II) At Sangam. Water has the following values for input parameters and their membership grades:

$$
\begin{gathered}
X=\left\{\left(x_{1}=4.6,0.92\right),\left(x_{2}=9.0,0.95\right),\left(x_{3}=3.4,0.99\right),\right. \\
\left.\left(x_{4}=8.35,0.65\right),\left(x_{5}=5000,0.61\right)\right\} .
\end{gathered}
$$

The quality of water at Sangam on Maghi Purnima is evaluated as below:

$$
\begin{aligned}
Y & =X \circ R \\
& =\left(\begin{array}{llll}
0.43 & 0.40 & 0.45 & 0.51
\end{array}\right),
\end{aligned}
$$

which states that water quality is very poor for bathing at Sangam.

(III) At Saraswati Ghat. Water has the following values for input parameters and their membership grades:

$$
\begin{gathered}
X=\left\{\left(x_{1}=4.2,0.96\right),\left(x_{2}=8.0,0.61\right),\left(x_{3}=1.8,0.84\right),\right. \\
\left.\left(x_{4}=8.22,0.69\right),\left(x_{5}=2600,0.76\right)\right\} .
\end{gathered}
$$

The quality of water at Saraswati Ghat on Maghi Purnima is evaluated as below:

$$
\begin{aligned}
Y & =X \circ R \\
& =\left(\begin{array}{llll}
0.29 & 0.38 & 0.41 & 0.45
\end{array}\right),
\end{aligned}
$$

which indicates that water quality is very poor for bathing at Saraswati Ghat.

A summary of water quality at different ghats is given in Table 5 .

\section{Conclusion}

The proposed information system is competent to give details of water quality for bathing and swimming throughout the year. It was tested during 2013 Maha Kumbh at Allahabad, as people take dip based on religious beliefs and faith in Supreme Power during the occasion of Maha Kumbh, and quality of water of these ghats was analysed on the basis of physicochemical and bacteriological combination. The informative system's output indicates that water quality of the said rivers during Maha Kumbh 2013 is worse than that during Ardha Kumbh 2007 at Allahabad [11].

\section{Conflict of Interests}

All authors, Pankaj Srivastava, Anjali Burande, and Neeraja Sharma, disclose that there is no conflict of interests. There are also neither financial nor personal relationships with other people or organizations mentioned in this work that could cause any inappropriate influence.

\section{References}

[1] C. Meyer, Evaluating Water Quality Using Spatial Interpolation Methods, Pinellas Country, Florida, USA, 2006.

[2] N. B. Harmancioglu, Y. Icaga, and A. Gul, "The use of an optimization method in assessment of water quality sampling sites," European Water Resource Association Journal, vol. 5, no. No6, pp. 25-34, 2004.

[3] K. Le. Rosemary, C. Rackauckas, and N. Ulloa, "Assessment of statistical methods for water quality monitoring in Marylands tidal waterways," SIAM Undergraduate Research, pp. 22-41.

[4] L. A. Zadeh, "Fuzzy sets," Information and Control, vol. 8, no. 3, pp. 338-353, 1965.

[5] R. Jain, "Decision making in the presence of fuzzy variables," IEEE Transactions on Systems, Man and Cybernetics, vol. 6, no. 10, pp. 698-703, 1976.

[6] R. E. Bellman and L. A. Zadeh, "Decision making in a fuzzy environment, Management Science," Management Science, vol. 17, no. 4, pp. B141-B164, 1970.

[7] S. Cho, O. K. Ersoy, and M. Lehto, "An algorithm to compute the degree of match in fuzzy systems," Fuzzy Sets and Systems, vol. 49, no. 3, pp. 285-299, 1992.

[8] M. Kumar, Application of Fuzzy Theory Approach to Study Water Pollution of Sangam Zone, M.Tech. Thesis Civil Engineering, Motilal Nehru National Institute of Technology, Allahabad, India, 2004.

[9] S. Yadav, Water quality assesment of water Ganga and Yamuna during Ardh Kumbh-2007 by Fuzzy Analysis [M.S. thesis], Environment Science, Allahabad University, 2007.

[10] D. Pandey, V. Mahajan, and P. Srivastava, "Rule-based system for cardiac analysis," National Academy Science Letters, vol. 29, no. 7-8, pp. 299-309, 2006.

[11] P. Srivastava and A. Srivastava, "A note on soft computing approach for cardiac analysis," Journal of Basic and Applied Scientific Research, vol. 2, no. 1, pp. 376-385, 2012.

[12] P. Srivastava and A. Srivastava, "Spectrum of soft computing risk assessment scheme for hypertension," International Journal of Computer Applications, vol. 44, no. 17, pp. 23-30, 2012.

[13] P. Srivastava and N. Sharma, "A spectrum of soft computing model for medical diagnosis," Applied Mathematics and Information Sciences. In press.

[14] P. Srivastava, A. Srivastava, and R. Sirohi, "Soft computing tools and classification criterion for hepatitis B," International Journal 
of Research and Reviews in Soft \& Intelligent Computing, vol. 2, no. 2, 2012.

[15] P. Srivastava, N. Sharma, and R. Singh, "Soft computing diagnostic system for diabetes," International Journal of Computer Applications, vol. 47, no. 18, pp. 22-27, 2012.

[16] E. Sanchez, "Medical diagnosis and composite fuzzy relations," in Advances in Fuzzy Set Theory and Application, M. M. Gupta, R. K. Ragade, and R. R. Yager, Eds., pp. 437-444, North Holland, Amsterdam, Netherlands, 1979.

[17] A. P. Rotshtein, M. Posner, and H. B. Rakytyanska, "Cause and effect analysis by fuzzy relational equations and a genetic algorithm," in Proceedings of International Conference on Fuzzy Logic and Its Application (FUZZY '97), pp. 125-130, 1997.

[18] L. A. Zadeh, The Concept of Linguistic Variable and Its Application to Approximate Decision Making, Mir, Moscow, Russia, 1976.

[19] A. Rotshtein, "Modication of Saaty method for the construction of fuzzy set membership functions," Reliability Engineering and System Safety, vol. 91, pp. 1095-1101, 1997. 

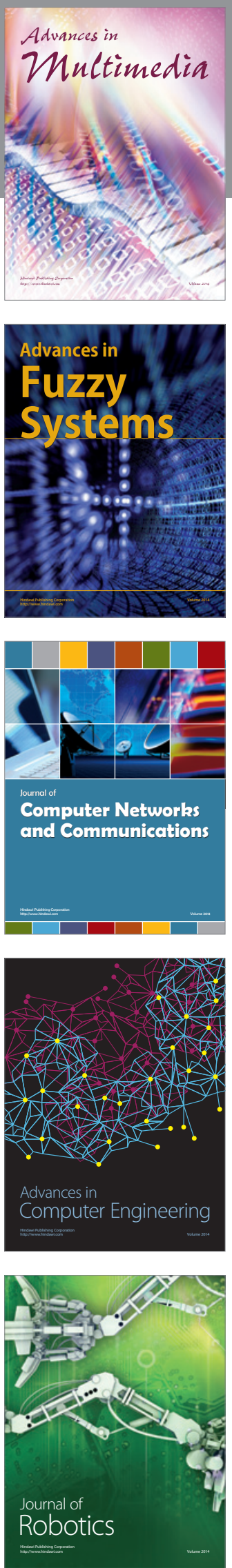

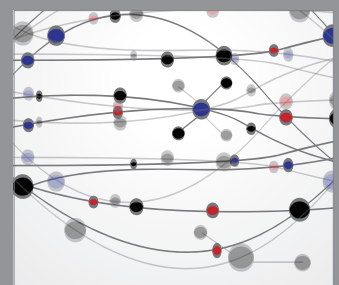

The Scientific World Journal
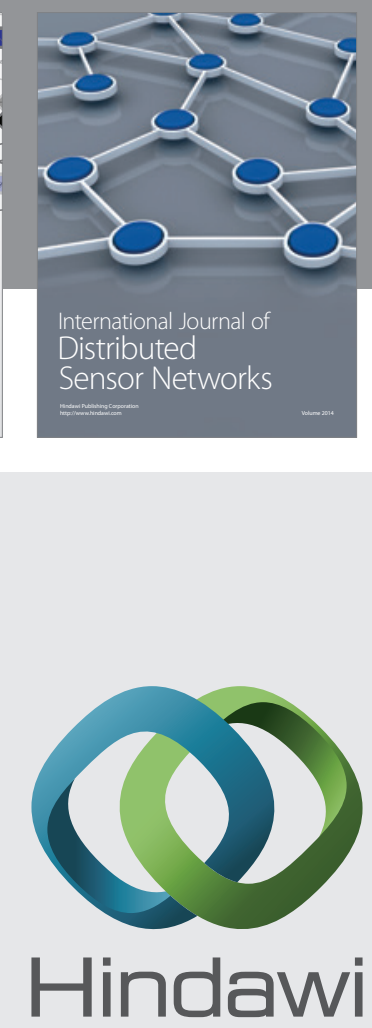

Submit your manuscripts at

http://www.hindawi.com
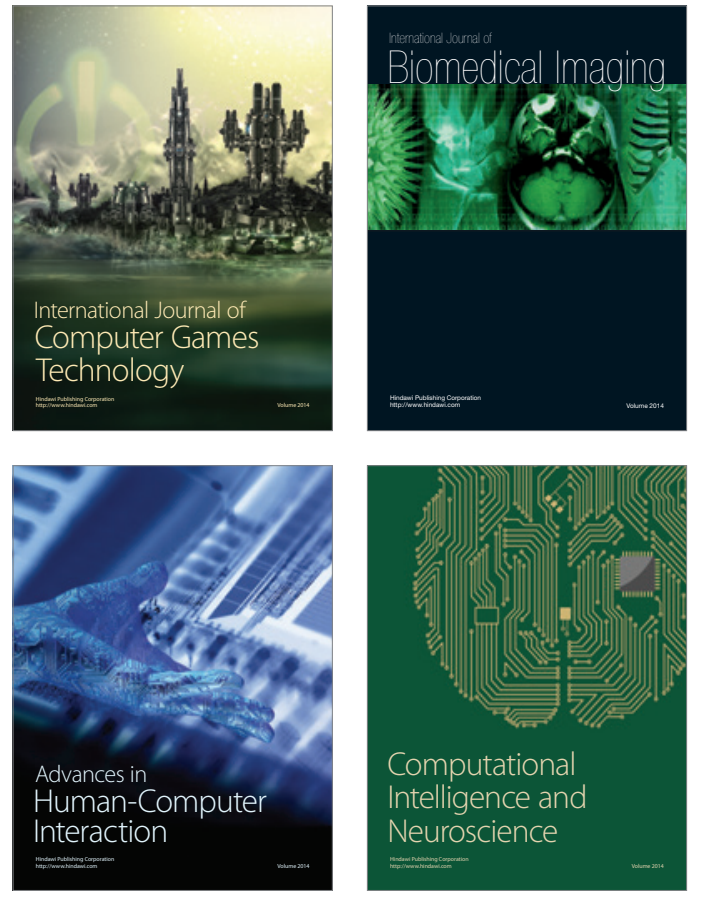
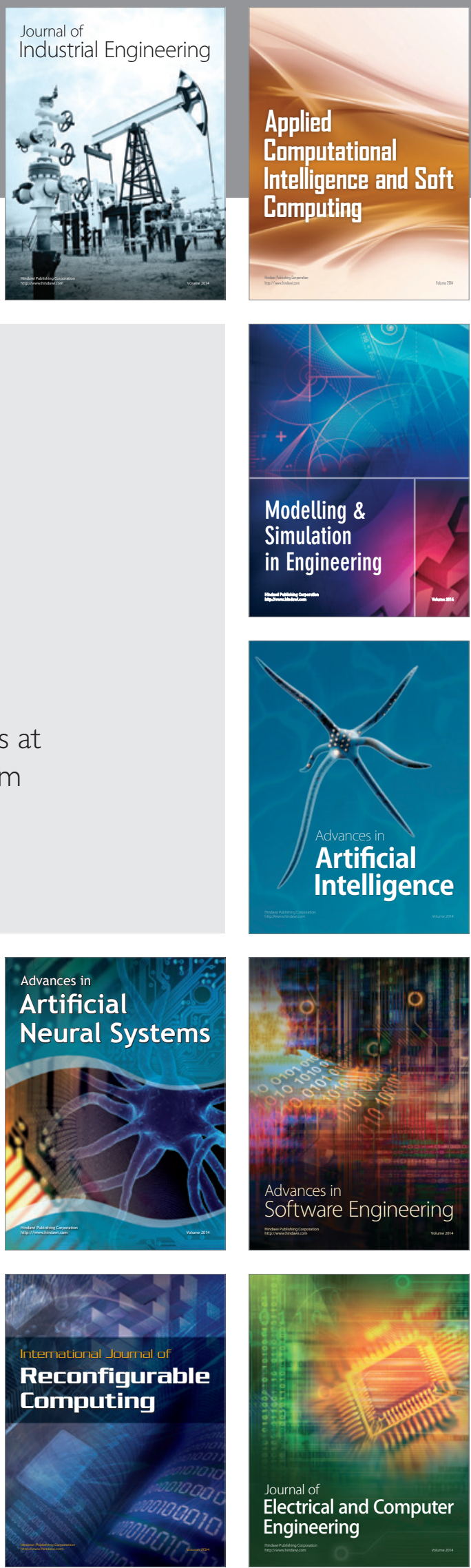